Check for updates

Cite this: RSC Adv., 2019, 9, 35452

Received 12th September 2019

Accepted 23rd October 2019

DOI: $10.1039 / c 9 r a 08602 a$

rsc.li/rsc-advances

\title{
Phase-transfer extraction for the fast quantification of perchlorate anions in water $\dagger$
}

\author{
J. Vázquez (iD) and V. Šindelár (D)*
}

Supramolecular approaches for the quantitative anion analysis in water remain scarce due to the lack of receptors that effectively bind anions in this medium. Herein, we present a novel, fast and easy, supramolecular approach for a selective and quantitative analysis of perchlorate anions in water, coupling the UV-Vis spectroscopic method and phase-transfer extraction of anions by a water-insoluble anion receptor.

During the past decades, supramolecular recognition of anions has developed rapidly, with an increasing number of reported receptors, ${ }^{1-4}$ applied also in analytical chemistry. ${ }^{5,6}$ These anion receptors often employ hydrogen bonding as the recognition element, and are seldom reported for aqueous solutions ${ }^{2}-$ a consequence of the challenging ion recognition due to the high solvation of anions as well the competition of water molecules for the binding site of the receptor. This may be circumvented by employing receptors that bare positive charges. ${ }^{7-12}$ However, due to the nondirectional electrostatic interactions and counterion competition for the binding site, neutral receptors incorporating weak interactions may offer a better alternative over charged receptors. In particular, neutral receptors relying on $\mathrm{C}-\mathrm{H}$ hydrogen bond interactions in combination with the hydrophobic effect possess excellent anion binding properties in water. A few examples include cyclopeptide derived hosts by Kubik, ${ }^{13,14}$ biotinuril macrocycles by Pittelkow, ${ }^{15,16}$ indolocarbazole-based foldamer by Jeong, ${ }^{17}$ phenylethynyl hosts by Johnson and Haley, ${ }^{18}$ octa-acids by Gibb, ${ }^{19}$ and the bambusuril macrocycles, introduced by our group in 2010, which exhibit very high binding affinity towards many anions both in organic and aqueous media. ${ }^{20-23}$

Conventional methods for the detection and quantification of anions in water are often time consuming, require complicated instrumentation, or frequently necessitate troublesome sample pre-treatment and reagent preparations..$^{24,25}$ Anions and cations in drinking water and environmental waters are mainly determined using the methods of capillary electrophoresis, ion chromatography, and mass spectrometry. ${ }^{24,26}$ However, these techniques exhibit disadvantages such as the presence of interferences, lengthy analysis, complex data interpretation, the usage of expensive stationary phases and/or large amounts of

Department of Chemistry, RECETOX, Faculty of Science, Masaryk University, Kamenice 5, 62500 Brno, Czech Republic. E-mail: sindelar@chemi.muni.cz

$\dagger$ Electronic supplementary information (ESI) available: Experimental details, UV/Vis and NMR graphs. See DOI: 10.1039/c9ra08602a mobile phases. ${ }^{24,27,28}$ In this respect, a simple method that combines supramolecular anion recognition, phase-transfer extraction, and widely available spectroscopic technique (i.e. UV/Vis), would, in principle, offer a very convenient approach to the quantification of anions in water samples. To our surprise, such method was unprecedented up to now, even though neutral receptors, such as crown ethers or calix $[n]$ pyrroles, have been widely used for the extraction or preconcentration of anions. ${ }^{29-31}$ In a few cases, ionic dyes facilitated the use of UV/ Vis spectroscopy to follow the extraction process, albeit only in a qualitative sense. ${ }^{32-34}$

Herein, we present a novel, fast and simple analytical method for the quantification of perchlorate anions in water via supramolecular anion recognition. The method comprises a biphasic solution system of water-insoluble anion receptor, bambusuril (BnBU), and a cationic lucigenin dye $\left(\mathbf{L u c}\left(\mathrm{NO}_{3}\right)_{2}\right.$, Scheme 1, Fig. 1), operating on the principle of selective extraction of $\mathbf{L u c}\left(\mathrm{ClO}_{4}\right)_{2}$ from the aqueous to the organic phase. This allowed a simple UV/Vis quantification of the remaining $\mathbf{L u c}^{2+}$ in water which is related to the perchlorate content.

The extraction of $\mathbf{L u c}^{2+}$ from water to the dichloromethane (DCM) solution of $\mathbf{B n B U}$, upon adding $\mathrm{NaClO}_{4}$, was in agreement with the disappearance of UV/Vis absorption bands of

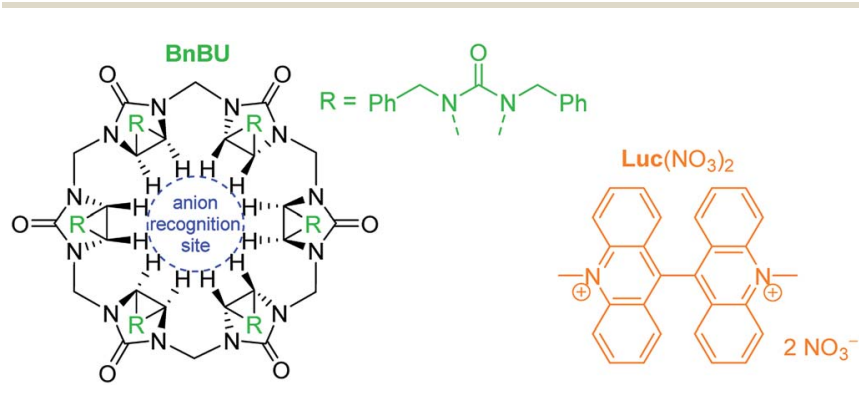

Scheme 1 The bambusuril anion receptor $(\mathrm{BnBU})$ and the lucigenin dye $\left(\mathrm{Luc}\left(\mathrm{NO}_{3}\right)_{2}\right)$ used for perchlorate quantification by phase-transfer extraction. 


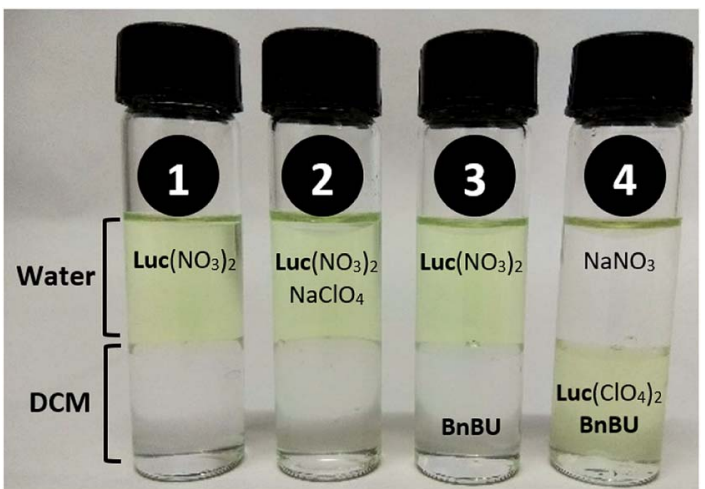

Fig. 1 Extraction experiments of the $\mathrm{Luc}^{2+}$ dye from water to dichloromethane (DCM), showing that both $\mathrm{BnBU}$ and perchlorate are necessary to extract $\mathrm{Luc}^{2+}$.

Luc $^{2+}$ (Fig. 2). Control experiments showed that, in the absence of $\mathrm{NaClO}_{4}$, only $5 \%$ of $\mathbf{L u c}^{2+}$ is extracted to the BnBU DCM solution (Fig. S1†). However, no extraction occurred in the absence of BnBU. This observation is likely explained by the extraction of nitrate via complexation to BnBU, accompanied by the $\mathbf{L u c}^{2+}$ counter-ions. The association constant for the $\mathrm{BnBU} \cdot \mathrm{NO}_{3}{ }^{-}$complex is more than one order of magnitude lower compared to that one of the $\mathbf{B n B U} \cdot \mathrm{ClO}_{4}{ }^{-}$complex in chloroform, ${ }^{21}$ which results in a poor extraction of $\mathbf{L u c}^{2+}$ in the form of a nitrate salt, but much greater extraction in the form of a perchlorate salt. Moreover, $\mathbf{L u c}^{2+}$ was still being extracted as a preferred counter-ion even in the competing environment having $\mathrm{Na}^{+}, \mathrm{K}^{+}, \mathrm{Mg}^{2+}$, or $\mathrm{Ca}^{2+}$ cations (Fig. $\mathrm{S} 2-\mathrm{S} 5 \dagger$ ), commonly found in drinking water.

Furthermore, sodium salts of other anions, namely, $\mathrm{Cl}^{-}, \mathrm{I}^{-}$, $\mathrm{H}_{2} \mathrm{PO}_{4}{ }^{-}, \mathrm{SO}_{4}{ }^{2-}, \mathrm{HCO}_{3}{ }^{-}$, and $\mathrm{NO}_{3}{ }^{-}$were also studied in the extraction experiments (Fig. S7-S12 $\dagger$ ) as these anions are naturally present in waters and biological fluids. No extraction was observed for the $\mathrm{Cl}^{-}, \mathrm{H}_{2} \mathrm{PO}_{4}{ }^{-}$, and $\mathrm{SO}_{4}{ }^{2-}$ (Fig. S7-S9 $\dagger$ ) because these anions bind to $\mathbf{B n B U}$ with low affinity due to their high solvation by water molecules. $\mathrm{NO}_{3}{ }^{-}$and $\mathrm{HCO}_{3}{ }^{-}$anions extracted only at much higher concentrations ( $>2 \mathrm{mM}$, Fig. S10 and $\mathrm{S11} \dagger)$ compared to perchlorate $(<50 \mu \mathrm{M})$. The extraction of

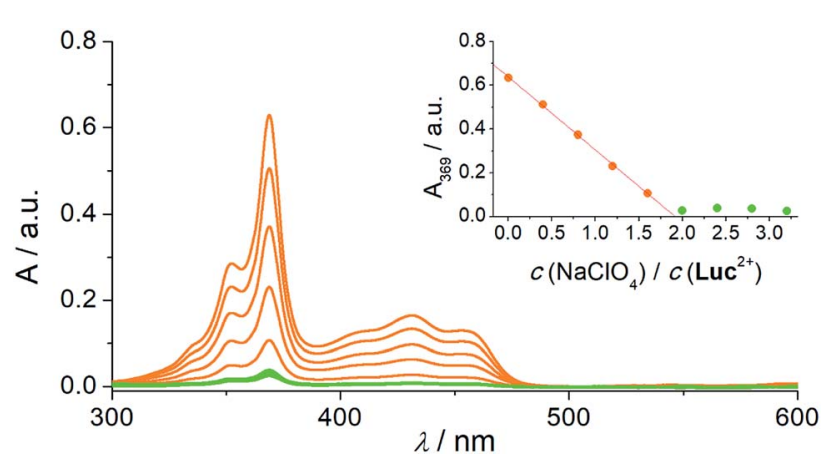

Fig. 2 UV-Vis spectra of water layers in a bi-phasic system (water/ DCM) with different content of $\mathrm{NaClO}_{4} / \mathrm{Luc}\left(\mathrm{NO}_{3}\right)_{2}$, in the presence of $\mathrm{BnBU}$. Intercept: absorbance data at $369 \mathrm{~nm}$. The straight line is a visual aid for the relevant linear region.
$\mathrm{NO}_{3}{ }^{-}$is due to its higher chaotropic nature while the $\mathbf{L u c}{ }^{2+}$ extraction via $\mathrm{HCO}_{3}{ }^{-}$was only partially achieved up to $\approx 30 \%$ even with a large excess of $\mathrm{HCO}_{3}{ }^{-}$(Fig. S10 $\dagger$ ). This may indicate additional acid-base equilibrium in the extractions process of $\mathrm{HCO}_{3}{ }^{-}$. Only I ${ }^{-}$anion exhibited a $\mathbf{L u c}^{2+}$ extraction to a significant extent at concentrations comparable to that of perchlorate $(<50 \mu \mathrm{M}$, Fig. S12 $\dagger)$. The affinity of tested anions towards BnBU is significantly weaker in comparison to perchlorate, with the exception of iodide, that binds with a similar strength. ${ }^{21}$ This indicates that the anion affinity towards BnBU plays an important role in the extraction process and it is following the order of these anions in the Hofmeister series. ${ }^{35}$ Therefore we decided to study the extraction of $\mathbf{L u c}^{2+}$ in presence of other chaotropic anions such as $\mathrm{BF}_{4}{ }^{-}$and $\mathrm{PF}_{6}{ }^{-}$. The results showed a rather quantitative extraction of Luc $^{2+}$ (Fig. S13 and S14 $\dagger$ ), suggesting that, even though chaotropic anions are far less common in aqueous solutions, they should be taken in consideration, since they might as well interfere with the methodology herein presented.

Spectral changes in the course of the extraction experiments, followed by UV/Vis spectroscopy (Fig. 2), exhibited a linear dependence of the absorbance versus perchlorate concentration, up to two-fold excess of $\mathrm{NaClO}_{4}$ with respect to $\mathbf{L u c}^{2+}$. This strongly indicates that the $\mathbf{L u c}^{2+}$ dication is extracted exclusively in a $1: 2$ stoichiometry ( $\mathbf{L u c}^{2+}$ : perchlorate). Since the absorbance is linearly proportional to the concentration of perchlorate, the titration curve could be used for the quantitative analysis of perchlorate in water (Fig. S6†).

We utilized the aforementioned findings for the determination of perchlorates in different aqueous media, containing 10 or $20 \mu \mathrm{M}$ of $\mathrm{NaClO}_{4}$ : (i) deionized water (MilliQ quality), (ii) saline water $(c(\mathrm{NaCl})=500 \mathrm{mM})$, and (iii) a solution mimicking conditions in blood plasma $\left(c(\mathrm{NaCl})=100 \mathrm{mM}, c\left(\mathrm{NaHCO}_{3}\right)=\right.$ $20 \mathrm{mM}$ ). The UV/Vis spectra of the water phases were recorded after the extraction procedure, and the perchlorate concentrations for each sample was calculated from the difference in the $\mathbf{L u c}^{2+}$ absorbance in the aqueous phase. The measurements,

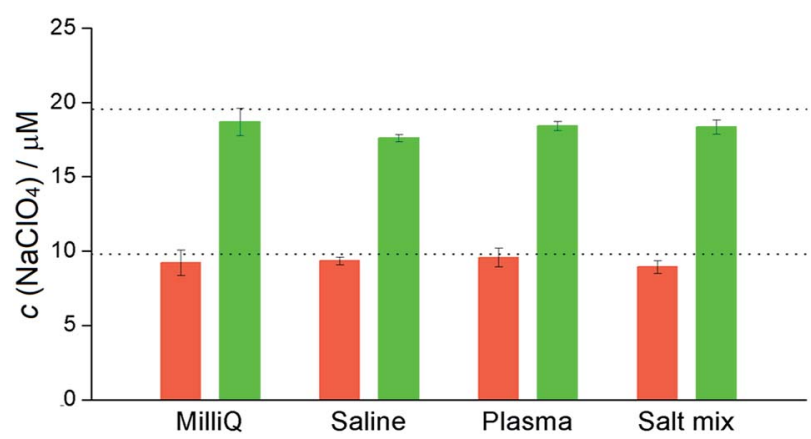

Fig. 3 Perchlorate content in different aqueous media, determined using the described $\mathrm{BnBU} / \mathrm{Luc}^{2+}$ supramolecular approach, showing very good agreement with the real perchlorate concentration (dotted lines). The red and green bars indicate 10 and $20 \mu \mathrm{M}$ of perchlorate in the samples, respectively. The abbreviated media correspond to the MilliQ water, saline $(c(\mathrm{NaCl})=500 \mathrm{mM})$, plasma $(c(\mathrm{NaCl})=100 \mathrm{mM}$, $c\left(\mathrm{NaHCO}_{3}\right)=20 \mathrm{mM}$ ), and a mixture of salts (cations: $\mathrm{Na}^{+}, \mathrm{K}^{+}, \mathrm{Mg}^{2+}$, $\mathrm{Ca}^{2+}$; anions: $\mathrm{Cl}^{-}, \mathrm{H}_{2} \mathrm{PO}_{4}{ }^{-}, \mathrm{SO}_{4}{ }^{2-}, \mathrm{HCO}_{3}{ }^{-}$, and $\mathrm{NO}_{3}{ }^{-}$). 
repeated in triplicates, were in very good agreement with the real perchlorate content (Fig. 3), with absolute errors of up to $-10 \%$ (saline media with $20 \mu \mathrm{M}$ of $\mathrm{NaClO}_{4}$ ).

As presented in previous paragraphs, individual anion/ cation influence on the extraction of $\mathbf{L u c}^{2+}$ indicated potentially selective behaviour of perchlorate. Therefore, the determination of perchlorate content in the presence of different anions and cations was further probed. Indeed, in a multiple salt mixture, namely, $\mathrm{Mg}\left(\mathrm{ClO}_{4}\right)_{2}, \mathrm{Na}_{2} \mathrm{SO}_{4}, \mathrm{CaCl}_{2}, \mathrm{KH}_{2} \mathrm{PO}_{4}$, $\mathrm{NaHCO}_{3}$, and $\mathrm{NaNO}_{3}$ (a detailed composition can be found in ESI, Fig. S18 $\dagger$ ), the extraction experiments gave very good agreement of the perchlorate content for both 10 and $20 \mu \mathrm{M}$ concentrations of perchlorate anions (Fig. 3). Therefore, the proposed extraction method is indeed suitable for the quantitative analysis of perchlorate content in water. The presence of iodide, however, is expected to be a relevant interference in the determination of perchlorate. In this case, the iodide and perchlorate contributions could be easily assessed by ${ }^{1} \mathrm{H}$ NMR. The ability of bambusurils to differentiate anions on NMR has been already reported previously by our group. ${ }^{21}$ The extraction experiment of a sample containing both $\mathrm{ClO}_{4}{ }^{-}$and $\mathrm{I}^{-}$, resulted in a $\mathbf{L u c}^{2+}$ extraction corresponding to the total concentration of these anions, the ratio of which was accurately determined by ${ }^{1}$ H NMR (Fig. S19 and S20 $)$ ).

In summary, a new supramolecular approach for the quantification of perchlorate in water has been demonstrated. Bambusuril anion receptor was employed in the phase-transfer extraction of anions into an organic solvent, based on their relative binding strength with the receptor. The organic dye, lucigenin, was used as an indicator of the anion extraction process, as it was selectively extracted as a counter-ion. The presented methodology is invariant towards common anionic or cationic interfering species. Very good results were obtained for the analysis of perchlorate anions in different matrices (pure water, saline, and plasma blood conditions). We believe the methodology could be generally applied for quantification of various water-soluble analytes, using different water insoluble receptors. The presented method may in principle be applied for simple routine analysis of perchlorates, as it shows superiority towards the usual analytical methods in both simplicity and speed, with satisfying accuracy.

\section{Conflicts of interest}

There are no conflicts to declare.

\section{Acknowledgements}

This work was supported by the Czech Science Foundation (1821801S) and the RECETOX Research Infrastructure (LM2015051 and CZ.02.1.01/0.0/0.0/16_013/0001761). We thank Zoran Kokan for the valuable remarks and discussions.

\section{Notes and references}

1 A. Brown and P. D. Beer, Chem. Commun., 2016, 52, 86458658.
2 M. J. Langton, C. J. Serpell and P. D. Beer, Angew. Chem., Int. Ed., 2016, 55, 1974-1987.

3 Q. He, P. Tu and J. L. Sessler, Chem, 2018, 4, 46-93.

4 M. Zhang, R.-L. Lin, W.-Q. Sun and J.-X. Liu, J. Inclusion Phenom. Macrocyclic Chem., 2018, 90, 173-187.

5 S. Li and W. C. Purdy, Chem. Rev., 1992, 92, 1457-1470.

6 L. Szente and J. Szemán, Anal. Chem., 2013, 85, 8024-8030.

7 M. A. Saeed, F. R. Fronczek and M. A. Hossain, Chem. Commun., 2009, 6409-6411, DOI: 10.1039/b916099j.

8 K. R. Dey, T. Horne, F. R. Fronczek and M. A. Hossain, Inorg. Chem. Commun., 2010, 13, 1515-1518.

9 R. Kumar, S. Kumar, P. Singh, G. Hundal, M. S. Hundal and S. Kumar, Analyst, 2012, 137, 4913-4916.

10 J. Cai, B. P. Hay, N. J. Young, X. Yang and J. L. Sessler, Chem. Sci., 2013, 4, 1560-1567.

11 H. Zhou, Y. Zhao, G. Gao, S. Li, J. Lan and J. You, J. Am. Chem. Soc., 2013, 135, 14908-14911.

12 V. Amendola, G. Bergamaschi, M. Boiocchi, R. Alberto and H. Braband, Chem. Sci., 2014, 5, 1820-1826.

13 S. Kubik, R. Goddard, R. Kirchner, D. Nolting and J. Seidel, Angew. Chem., Int. Ed., 2001, 40, 2648-2651.

14 F. Sommer and S. Kubik, Org. Biomol. Chem., 2014, 12, 88518860 .

15 M. Lisbjerg, B. M. Jessen, B. Rasmussen, B. E. Nielsen, A. Ø. Madsen and M. Pittelkow, Chem. Sci., 2014, 5, 26472650.

16 M. Lisbjerg, B. E. Nielsen, B. O. Milhøj, S. P. A. Sauer and M. Pittelkow, Org. Biomol. Chem., 2015, 13, 369-373.

17 J.-m. Suk and K.-S. Jeong, J. Am. Chem. Soc., 2008, 130, 11868-11869.

18 O. B. Berryman, C. A. Johnson II, L. N. Zakharov, M. M. Haley and D. W. Johnson, Angew. Chem., Int. Ed., 2008, 47, 117-120.

19 P. Sokkalingam, J. Shraberg, S. W. Rick and B. C. Gibb, J. Am. Chem. Soc., 2016, 138, 48-51.

20 J. Svec, M. Necas and V. Sindelar, Angew. Chem., Int. Ed., 2010, 49, 2378-2381.

21 V. Havel and V. Sindelar, ChemPlusChem, 2015, 80, 16011606.

22 M. A. Yawer, V. Havel and V. Sindelar, Angew. Chem., Int. Ed., 2015, 54, 276-279.

23 J. Vazquez and V. Sindelar, Chem. Commun., 2018, 54, 58595862.

24 M. L. Magnuson, E. T. Urbansky and C. A. Kelty, Anal. Chem., 2000, 72, 25-29.

25 Y. Yang, F. Huo, J. Zhang, Z. Xie, J. Chao, C. Yin, H. Tong, D. Liu, S. Jin, F. Cheng and X. Yan, Sens. Actuators, B, 2012, 166-167, 665-670.

26 R. Srinivasan and G. A. Sorial, Sep. Purif. Technol., 2009, 69, 7-21.

27 A. Padarauskas, V. Olsauskaite and V. Paliulionyte, J. Chromatogr. A, 1998, 829, 359-365.

28 F. A. Mellon, in Encyclopedia of Food Sciences and Nutrition, ed. B. Caballero, Academic Press, Oxford, 2nd edn, 2003, pp. 3739-3749, DOI: 10.1016/B0-12-227055-X/00746-X.

29 Q. He, Z. Zhang, J. T. Brewster, V. M. Lynch, S. K. Kim and J. L. Sessler, J. Am. Chem. Soc., 2016, 138, 9779-9782. 
30 H. Zhou, Y. Wang, X. Guo, Y. Dong, X. Su and X. Sun, J. Mol. Liq., 2018, 254, 414-420.

31 W. Zhu, Y. Jia, Q. Zhang, J. Sun, Y. Jing and J. Li, J. Mol. Liq., 2019, 285, 75-83.

32 I. Carreira-Barral, M. Mato-Iglesias, A. de Blas, C. PlatasIglesias, P. A. Tasker and D. Esteban-Gómez, Dalton Trans., 2017, 46, 3192-3206.
33 S. Mahajan, N. Singh, J. P. Kushwaha and A. Rajor, Chem. Eng. Commun., 2019, 206, 697-707.

34 G. A. Marcelo, S. M. G. Pires, M. A. F. Faustino, M. M. Q. Simões, M. G. P. M. S. Neves, H. M. Santos, J. L. Capelo, J. P. Mota, C. Lodeiro and E. Oliveira, Dyes Pigm., 2019, 161, 427-437.

35 F. Hofmeister, Arch. Exp. Pathol. Pharmakol., 1888, 24, 247260. 